\title{
IMPLIKASI KEBIJAKAN RELOKASI KAPAL IZIN PUSAT TERHADAP NELAYAN LOKAL DI KEPULAUAN ARU
}

\section{Policy Implications of Relocating Centralized Vessels Licensie to Local Fishers in the Aru Islands}

\author{
*Christina Yuliaty, Nendah Kurniasari, Rizky Muhartono dan Fatriyandi N. Priyatna \\ Balai Besar Riset Sosial Ekonomi Kelautan dan Perikanan \\ Gedung BRSDM KP I Lt. 4 \\ Jalan Pasir Putih Nomor 1 Ancol Timur, Jakarta Utara, Indonesia \\ Telp: (021) 64711583 Fax: 64700924
}

Diterima tanggal: 20 Nopember 2018 Diterima setelah perbaikan: 18 Maret 2019

Disetujui terbit: 26 Juni 2019

\begin{abstract}
ABSTRAK
Kebijakan yang diambil Kementerian Kelautan Perikanan berupa relokasi wilayah tangkap kapal berijin pusat ( > $30 \mathrm{GT}$ ) dari WPP 712 ke wilayah-wilayah yang dianggap masih mempunyai sumberdaya perikanan yang lebih moderat, di antaranya ke WPP 718 memberikan dampak bagi masyarakat di wilayah tujuan relokasi. Tulisan ini bertujuan untuk memaparkan implikasi nelayan pendatang terhadap relasi dan pola usaha nelayan lokal yang berada di Kepulauan Aru. Kajian ini dilakukan di Kota Dobo dan beberapa desa di Kepulauan Aru sebagai salah satu lokasi relokasi kapal berijin pusat. Penelitian ini bersifat deskriptif kualitatif. Penelitian ini berupaya memberikan gambaran kondisi secara nasional, meskipun pendalaman dilakukan pada lokasi sampel yang terbatas. Hasil penelitian memperlihatkan jumlah kapal berijin pusat di Wilayah Pengelolaan Perikanan 718 mengalami kenaikan yang sangat signifikan yaitu 293,2\% selama periode 2015-Maret 2018 dan terdapat potensi konflik terkait perebutan ruang tangkapan dan perubahan terhadap potensi relasi produksi ilegal.
\end{abstract}

Kata Kunci: kebijakan relokasi kapal ijin pusat; nelayan lokal; Kepulauan Aru

\section{ABSTRACT}

The policy of Ministry of Marine Affairs and Fisheries to relocate the capture areas of in central licensed vessels (> 30 GT) from Fisheries Management Area (WPP) 712 to other more moderate fishery areas including to WPP 718 gives an impact on communities in the destination areas. This paper aims to describe the implications of migrant fishers on the relations and business patterns of local fishers in the Aru Islands. This study was conducted in Dobo City and several villages in the Aru Islands as one of destination fishing area. This is a descriptive qualitative reserach. This study gives an overview of national condition, even though more comprehensive analysis focused on limited sample location. The results showed a significant increase in the number of central licensed vessels in the WPP 718 Fisheries Management Region of 293.2\% during 2015 to March 2018. This study also found potential conflicts related to struggle for fishing areas and changes to the potential of illegal production.

Keywords: relocation of central licensed vessel; local fishers; Aru Islands

\section{PENDAHULUAN}

Kementerian Kelautan dan Perikanan (KKP) telah mengeluarkan aturan berupa Peraturan Menteri Kelautan dan Perikanan No. 71 Tahun 2016 tentang tentang Jalur Penangkapan Ikan dan Penempatan Alat Penangkapan Ikan di Wilayah Pengelolaan Perikanan Negara Republik Indonesia. Aturan ini bermaksud mengatur pemanfaatan sumber daya ikan yang bertanggung jawab, optimal dan berkelanjutan serta mengurangi konflik pemanfaatan sumber daya ikan berdasarkan prinsip pengelolaan sumber daya ikan. Pengaturan jalur penangkapan disesuaikan dengan hasil perhitungan estimasi potensi sumberdaya ikan di masing-masing wilayah pengelolaan perikanan (WPP) yang tertuang dalam Keputusan Menteri Kelautan dan Perikanan No. 50 Tahun 2017 tentang estimasi potensi jumlah tangkapan yang diperbolehkan dan tingkat pemanfaatan sumber daya ikan di WPP-NRI. Berdasarkan hal tersebut, maka pemerintah dalam hal ini KKP mengatur kegiatan relokasi wilayah tangkap kapal -kapal dari WPP 712 ke wilayah-wilayah yang dianggap 
masih mempunyai sumberdaya perikanan yang lebih moderat, di antaranya ke WPP 718.

Kapal-kapal yang dikenakan aturan relokasi wilayah penangkapan adalah kapal yang memiliki izin pusat yaitu kapal > 30 GT termasuk di dalamnya kapal-kapal eks cantrang yang berukuran > 30 GT yang telah dirubah alat tangkapnya dan diberikan ijin baru penangkapan pada Wilayah Pengolaan Perikanan (WPP) 711 dan 718. Aturan ini merupakan implementasi dari Surat Edaran Direktur Jenderal Perikanan Tangkap Nomor B.664/DJPT/PI.220/VI/2017 Tanggal 19 Juni 2017 Tentang Perpanjangan Masa Peralihan Alat Penangkapan Ikan Pukat Tarik Dan Pukat Hela Di WPPNRI.

Penetapan perairan Arafura dan sekitar Kabupaten Kepulauan Aru menjadi salah satu wilayah tujuan penangkapan pada kebijakan penyesuaian wilayah fishing ground dari WPP 712 keWPP718, didasarkan pada pertimbangan wilayah tersebut masih memiliki pasokan sumberdaya yang cukup. Kegiatan relokasi wilayah tangkap merupakan langkah strategis yang diambil oleh pemerintah sebagai jalan keluar saat menghadapi masalah tekanan sumberdaya di sebuah perairan. Aktivitas relokasi ini, tentunya akan berpengaruh terhadap kondisi sosial ekonomi nelayan baik pada komunitas nelayan yang melakukan relokasimaupun komunitas nelayan di wilayah tujuan relokasi. Gunawan, Ruyadi \& Alia, (2017) mengemukakan bahwa sosial-ekonomi merupakan segala sesuatu yang berhubungan dengan pemenuhan kebutuhan yang ada di masyarakat atau lebih umumnya terkait dengan kesejahteraan masyarakat. Dalam hal ini, nelayan dalam melakukan aktivitas ekonomi dalam hal ini adalah aktivitas penangkapan ikan, pasti akan melakukan interaksi dan hubungan sosial yang kemudian membentuk jejaring dalam rangka memenuhi kebutuhannya.

Upaya relokasi wilayah tangkap ke WPP 718, tidak hanya berdampak positif berupa berkurangnya tekanan terhadap sumberdaya di WPP 712, namun juga diindikasikan membawa dampak negatif terutama di daerah tujuan relokasi. Dilansir dari laman Dewan Perwakilan Rakyat (DPR) RI (2018) diketahui bahwa Komisi IV DPR RI menemukan adanya kecemburuan nelayan tradisional di Kepulauan Aru terhadap nelayan eks cantrang dari Jawa yang mempunyai fasilitas kapal yang lebih besar. Nelayan lokal di perairan Aru sebagian besar merupakan nelayan one day fishing yang menggunakan perahu < 5 GT dengan alat tangkap yang sederhana. Peningkatan jumlah kapal berizin pusat dengan ukuran > 30 GT dengan alat tangkap yang jauh lebih modern dibandingkan dengan teknologi nelayan lokal, diprediksi akan memberikan pengaruh pada kehidupan nelayan lokal yang selama ini menangkap ikan di wilayah perairan Aru.

Berdasarkan hal tersebut, makalah ini bertujuan untuk memaparkan implikasi datangnya nelayan pendatang terhadap relasi dan pola usaha nelayan lokal yang berada di Kepulauan Aru. Makalah ditulis berdasarkan hasil penelitian yang dilakukan penulis pada Bulan Februari 2018 di Kota Dobo dengan pertimbangan perairan di sekitar wilayah tersebut merupakan lokasi tujuan program relokasi kapal > $30 \mathrm{GT}$, dan Kepulauan Aru merupakan sentra nelayan tradisional. Peneliti menggunakan tehnik observasi dan wawancara dalam mengumpulkan data primer. Observasi adalah suatu cara pengumpulan data dengan pengamatan langsung dan pencatatan secara sistematis terhadap obyek yang diteliti tanpa pertolongan standar lain untuk keperluan tersebut (Nasir, 2005). Observasi dilakukan oleh peneliti dengan cara pengamatan dan pencatatan mengenai kegiatan yang sehari-hari dilakukan oleh nelayan atau masyarakat. Cara yang paling efektif dalam melakukan pengamatan langsung adalah melengkapi format atau blangko pengamatan sebagai instrumen. Format yang disusun berisi item-item tentang kejadian atau tingkah laku yang terjadi (Arikuntho, 2006). Metode wawancara merupakan suatu percakapan yang dilakukan dengan maksud tertentu, dan biasanya percakapan ini dilakukan oleh dua belah pihak yaitu pewawancara dan terwawancara yang memberikan jawaban atas pertanyaan itu (Moleong, 2005). Wawancara dilakukan dengan nelayan untuk mengetahui permasalahan yang dihadapi oleh masyarakat, tanggapan masyarakat mengenai permasalahan penelitian, dan solusi yang masyarakat harapkan dapat diimplementasikan. Peneliti melakukan joting terhadap hasil wawancara baik berupa rekaman maupun catatan untuk kemudian di analisis. Hasil pengambilan data melalui observasi dan wawancara didokumentasikan dalam bentu foto, rekaman, video kegiatan pelaksanaan penelitian, dan catatan-catatan hasil observasi dan wawancara.

Data primer yang dikumpulkan berupa karakteriktik usaha nelayan lokal, nelayan pendatang, pedagang, dan perusahaan perikanan untuk menggambaran pola produksi dan 
relasi produksi perikanan di kota Dobo. Guna menganalisis implikasi nelayan pendatang terhadap nelayan lokal di Kepulauan Aru, peneliti memperoleh data primer melalui observasi lapang dan wawancara dengan pemangku kepentingan seperti pemerintah daerah, nelayan lokal, nelayan pendatang, pedagang serta perusahaan penampung ikan hasil tangkapan. Data sekunder diperoleh dari institusi terkait perijinan kapal yang diperoleh dari Direktorat Jenderal Perikanan Tangkap, dokumen perijinan dari Pemerintah Daerah, serta catatan keluar masuk kapal, produksi serta catatan pelanggaran dari PSDKP Wilayah Kerja Kota Dobo.

Analisis data dilakukan dengan cara deskriptif analysis. Tahapan yang dilakukan dalam analisis dekriptif menurut Miles \& Haberman (1992) adalah mereduksi data yang sudah terkumpul, penyajian data dengan mengorganisasikan data, dan terakhir menarik keterkaitan antar kelompok data dan diinterpretasikan secara logic untuk ditarik sebuah kesimpulan sebagai jawaban dari rumusan masalah. Meskipun pendalaman dilakukan pada lokasi sampel yang terbatas, namun penelitian berupaya memberikan rekomendasi skala nasional. Karena itu, selain data primer lapangan, peneliti memanfaatkan informasi sekunder, yakni berbagai laporan kegiatan dan hasil-hasil penelitian berkenaan dengan program-program perlindungan yang sudah berjalan selama ini di pusat dan daerah.

Penelitian ini merupakan penelitian berkaitan dengan kebijakan (research for policy) karena ditujukan untuk mengkaji aspek sosial terhadap nelayan lokal di Kota Dobo akibat kebijakan pengalihan wilayah tangkap (fishing ground) kapal berukuran > 30 GT dari Perairan WPP 712 ke WPP 718. Menurut Dunn (2000), analisis kebijakan merupakan suatu disiplin ilmu sosial terapan yang menggunakan berbagai macam metode penelitian dan argumen. Sedangkan menurut Weimer \& Vining (1998) analisis kebijakan publik seperti ini merupakan nasehat atau bahan pertimbangan pembuat kebijakan publik yang berisi tentang masalah yang dihadapi, tugas yang mesti dilakukan berkaitan dengan masalah tersebut, dan juga berbagai alternatif kebijakan yang mungkin bisa diambil dengan berbagai penilaiannya berdasarkan tujuan kebijakan.

Analisis ini bertujuan memberikan rekomendasi untuk membantu para pembuat kebijakan dalam upaya memecahkan masalah- masalah di lapangan. Sesuai dengan klasifikasi Dunn (2000), maka ini merupakan kegiatan analisis kebijakan prospektif, yakni berupa produksi dan transformasi informasi sebelum aksi kebijakan dimulai dan diimplementasikan. Hasil penelitian merupakan alat untuk mensintesakan informasi untuk dipakai dalam merumuskan alternatif dan preferensi kebijakan yang dinyatakan secara komparatif, diramalkan dalam bahasa kuantitatif dan kualitatif sebagai landasan atau penuntun dalam pengambilan keputusan kebijakan.

\section{Gambaran Umum Kepulauan Aru dan WPP 718}

Kepulauan Aru merupakan sebuah kabupaten baru yang muncul hasil pemekaran Kabupaten Maluku Tenggara melalui UndangUndang Nomor 40 Tahun 2003. Kabupaten Kepulauan Aru dengan kota Dobo sebagai ibukota kabupaten. Kabupaten Kepulauan Aru, terdiri dari gugusan pulau-pulau dengan lima buah pulau besar yaitu Pulau Wokam, Trangan, Kobror, Maekor dan Kota. Secara keseluruhan Kabupaten ini terdiri dari 547 pulau dengan 87 pulau diantaranya berpenghuni. Pulau-pulau tersebut tersebar dalam 10 kecamatan, 117 desa, dan 2 kelurahan.

Posisi Kota Dobo dan Kabupaten Kepulauan Aru sangat strategis dalam wilayah pengelolaan perikanan (WPP) 718. Kabupaten Kepulauan Aru terletak di $5^{\circ}-8^{\circ}$ Lintang Selatan dan $133^{\circ} 5^{\prime}$ - $136^{\circ} 5^{\prime}$ Bujur Timur. Batas wilayah administrasi Kabupaten Kepulauan Aru di Utara berbatasan dengan Provinsi Papua, bagian Barat berbatasan dengan Pulau Kei Besar, Kabupaten Maluku Tenggara, bagian Timur berbatasan dengan Provinsi Papua, dan pada bagian selatan berbatasan dengan Laut Arafura.

Berdasarkan Peraturan Menteri KP No.1 Tahun 2009 jo Permen No.18 Tahun 2014 tentang Wilayah Pengelolaan Perikanan Republik Indonesia mengasumsikan wilayah pengelolaan perikanan (WPP) sebagai satu unit stok yang harus dikelola oleh wilayah administrasi di seputarnya. Perairan Kepulauan Aru merupakan bagian dari WPP 718 bersama Laut Aru, Laut Arafuru, dan Laut Timor bagian Timur. Berdasarkan hasil kajian Suman, Irianto, Satria \& Amri, (2016). WPP 718 memiliki potensi sumber daya ikan tertinggi dibandingkan 10 WPP lainnya yaitu sebesar 1,992 juta ton/ tahun (20\%). Sebagian besar perairan ini masuk dalam perairan Provinsi Maluku dan Papua yang memiliki potensi sumber daya ikan demersal dan ikan karang. 
Potensi sumber daya ikan yang tinggi membuat WPP 718 menjadi salah satu wilayah tujuan penangkapan, terutama kapal-kapal berukuran > 30 GT yang berijin pusat. Terbukti saat ini Pelabuhan Dobo menjadi salah satu pelabuhan tempat bersandar kapal > 30 GT yang berasal dari Pulau Jawa. Siaran Pers Direktur Jenderal Perikanan Tangkap menyatakan bahwa 1100 kapal eks pengguna cantrang dari berbagai daerah saat ini diarahkan untuk mencari ikan di perairan Dobo yang masuk dalam Wilayah Pengelolaan Perikanan (WPP) 718. Peningkatan jumlah kapal berijin pusat di WPP 718 yang cukup signifikan diperlihatkan pada Gambar 1.

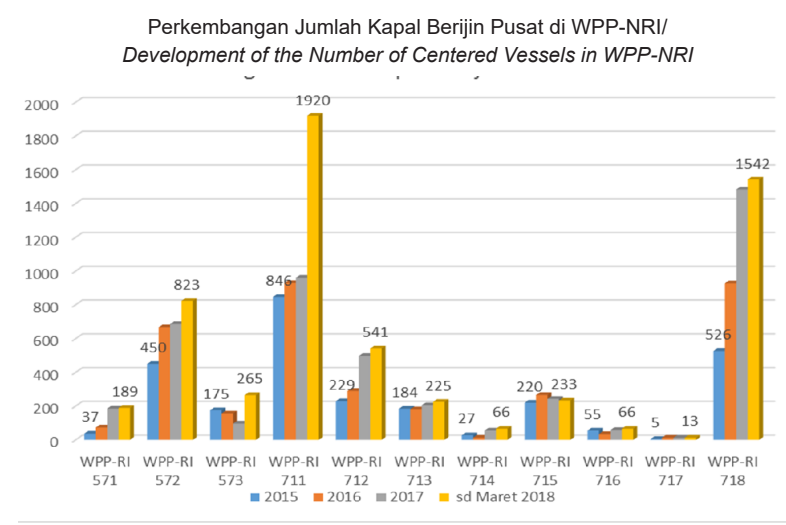

Gambar 1. Perkembangan Jumlah Kapal Berijin Pusat di WPP- NRI.

Figure 1. Development of the Number of Centered Vessels in WPP-NRI.

Sumber: DJPT, 2018./Source: DJPT, 2018.

Gambar 1 memperlihatkan bahwa pada periode 2015- Maret 2018 terjadi peningkatan jumlah kapal berijin pusat di WPP 718 sebesar 1016 kapal ( 293,2\%) yang tersebar di beberapa landing base di antaranya Dobo, Merauke,dan Kaimana. Data dari PSDKP Wilayah Kerja Dobo (2018) memperlihatkan bahwa kedatangan kapal berijin pusat dan propinsi yang beroperasi di Kabupaten Kepulauan Aru juga mengalami peningkatan jumlah.

Data lainnya diperlihatkan dari data frekuensi kapal yang datang di Kabupaten Kepulauan Aru yang memperlihatkan kenaikan jumlah kapal berijin pusat di perairan Dobo hanya terjadi pada bulan-bulan tertentu. Peningkatan frekuensi terjadi pada bulan September hingga Desember yang merupakan musim banyaknya ikan pelagis kecil.
Ikan tersebut merupakan ikan target dari kapal pendatang yang sebagian besar menggunakan alat tangkap purse seine.

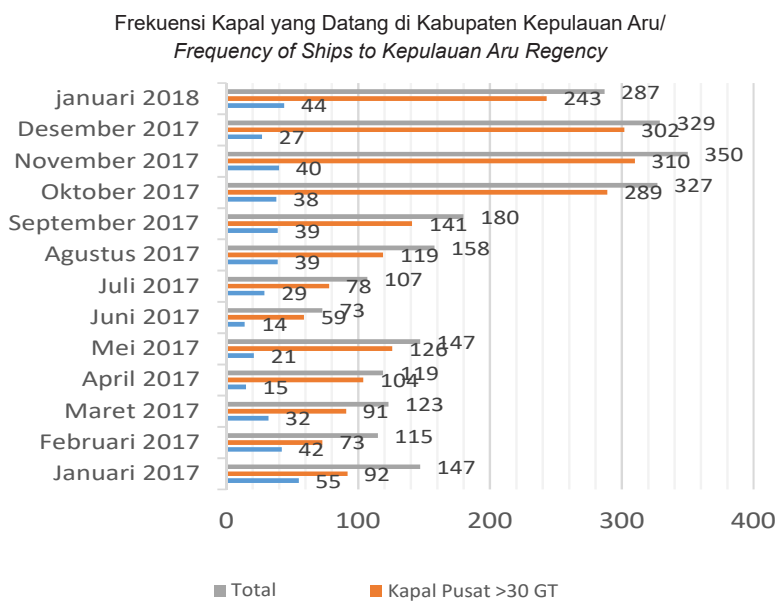

Gambar 2. Frekuensi Kapal yang Datang di Kabupaten Kepulauan Aru.

Figure 2. Frequency of Ships to Kepulauan Aru Regency.

Sumber: PSDKP Wilker Dobo, 2018./Source: PSDKP Wilker Dobo, 2018.

Berdasarkan besarnya GT kapal pendatang yang masuk ke perairan Dobo, kapal tersebut tidak bisa dikategorikan sebagai nelayan andon karena kapasitas kapalnya lebih dari 30 GT. Kenaikan jumlah kapal berijin pusat di perairan Dobo hanya terjadi pada bulan-bulan tertentu. Peningkatan frekuemsi terjadi pada bulan September hingga Desember yang merupakan musim banyaknya ikan pelagis kecil. Ikan tersebut merupaka ikan target dari kapal pendatang yangs ebagain besar menggunakan alat tangkap purse seine. Wilayah perairan tersebut merupakan wilayah penangkapan secara legal tanpa harus mengurus perijinan penangkpaan di wilayah provinsi, dan atau tanpa harus disertai MoU antara provinsi asal kapal dengan provinsi daerah tujuan.

\section{Musim Penangkapan}

Nelayan di Kabupaten Kepulauan Aru membagi musim penangkapan ke dalam 2 musim berdasarkan pengetahuan nelayan mengenai angin yaitu musim barat dan musim timur. Musim menentukan lokasi penangkapan ikan dan musim ikan. Musim Barat berlangsung dari bulan Oktober hingga Maret yang ditandai dengan ombak yang tinggi, curah hujan tinggi, angin kencang namun

1Sumber http://kmsv2.sosialekonomi.com/2018/03/13/ratusan-kapal-eks-cantrang-dari-jawa-melaut-di-perairan-dobo-aru-kenapa/ 
sumberdaya ikan melimpah. Pada musim barat, nelayan mensiasati kegiatan penangkapan pada saat angin/ombak mereda, dan ada pula nelayan yang beralih menggunakan alat tangkap sero selama musim barat. Lokasi pembuatan sero berada didekat rumah nelayan.

Musim Timur berlangsung dari bulan April hingga September, ditandai dengan curah hujan rendah dan ombak yang tidak terlalu tinggi. Pada musim ini, nelayan tetap melakukan kegiatan penangkapan seperti biasa.

Pada Tabel 1 terlihat bahwa ikan-ikan dasar/ karang dapat ditangkap oleh nelayan sepanjang tahun. Ikan pelagis seperti kembung, tongkol banyak ditangkap pada bulan Januari s/d Maret dan Oktober s/d Desember. Telur ikan terbang terdapat pada bulan April s/d Agustus dan Tenggiri pada bulan September s/d Desember.

\section{Karakteristik Nelayan di Kepulauan Aru}

Masyarakat nelayan Kepulauan Aru membedakan nelayan ke dalam tiga kelompok, yaitu: nelayan asli dan lokal; nelayan pendatang dari sulawesi dan nelayan pendatang dari Jawa.

\section{Nelayan Asli}

Nelayan asli adalah nelayan yang berasal dari suku Aru. Mereka umumnya nelayan yang menggunakan perahu di bawah 5 GT yang digunakan oleh 1-2 orang. Alat tangkap yang dipakai masih sederhana seperti jaring dan pancing, dengan hasil tangkapan berupa demersal dan ikan karang. Ririhena (2017) mengungkapkan bahwa di perairan Kepuluan Aru pada radius 0-12 mil jenis ikan demersal yang tertangkap adalah kakap merah, semntara untuk ikan karang adalah kerapu dan udang.

Nelayan asli tersebar di pulau-pulau kecil, dan masih menggunakan mekanisme sasi di daerah petuanan dalam mengelola sumberdaya perairannya. Hal ini didukung oleh penelitian Cantika, Arifin, Prayoga \& Sanjaya, (2017) bahwa Area penangkapan ikan (fishing ground) masyarakat adat masuk ke dalam wilayah adat atau patuanan marga sehingga aturan dan pengelolaannya dibawah kewenangan tetua adat atau kepala desa. Oleh karenanya nelayan ini sebagian besar tidak terpengaruh oleh maraknya nelayan pendatang dari Jawa.

\section{Nelayan Lokal}

Berdasarkan pemahaman Masyarakat, nelayan asli adalah nelayan yang berasal dari suku Aru. Mereka umumnya nelayan yang menggunakan perahu di bawah 5 GT dengan alat tangkap yang masih sederhana seperti jaring dan pancing. Satu armada digunakan oleh 1-2 orang. Sementara yang disebut dengan nelayan lokal yaitu nelayan yang bukan asli suku Aru (non Suku Aru) yang sudah lama menetap di Dobo dan sekitarnya namun telah memiliki kartu identitas sebagai warga Dobo. Nelayan lokal Aru tersebar di pulau-pulau yang ada di Kepulauan Aru sebagian besar menggunakan perahu dari fiber dengan ukuran panjang 9 meter dan lebar $80 \mathrm{~cm}$ dan dilengkapi dengan mesin tempel berkapasitas 15 PK. Perahu biasa disebut dengan 'longboat'. Perahu model lainnya yang biasa digunakan adalah ketinting panjang yang terbuat dari kayu dengan panjang 5-6 meter dan lebar $50 \mathrm{~cm}$ serta menggunakan mesin tarik berkekuatan 6,5 pk. Alat tangkap yang umumnya digunakan pancing dan jaring udang (trammel net) dengan target tangkapan ikan karang dan udang.Nelayan lokal merupakan nelayan one day fishing yang berangkat mencari ikan pada pukul 05.00 WIT dan pulang pada pukul 10.00 WIT. Perahu dan alat tangkap yang sederhana membuat nelayan lokal hanya mampu menangkap ikan di wilayah pesisir hingga $<2$ mil. Hal ini membuat nelayan lokal Aru yang tersebar di pulau tidak merasakan secara langsung dampak kedatangan nelayan pendatang di perairan Aru.

Tabel 1. Jadwal Tangkapan Ikan Berdasarkan Musim.

Table 1. Seasonal Fishing Schedule.

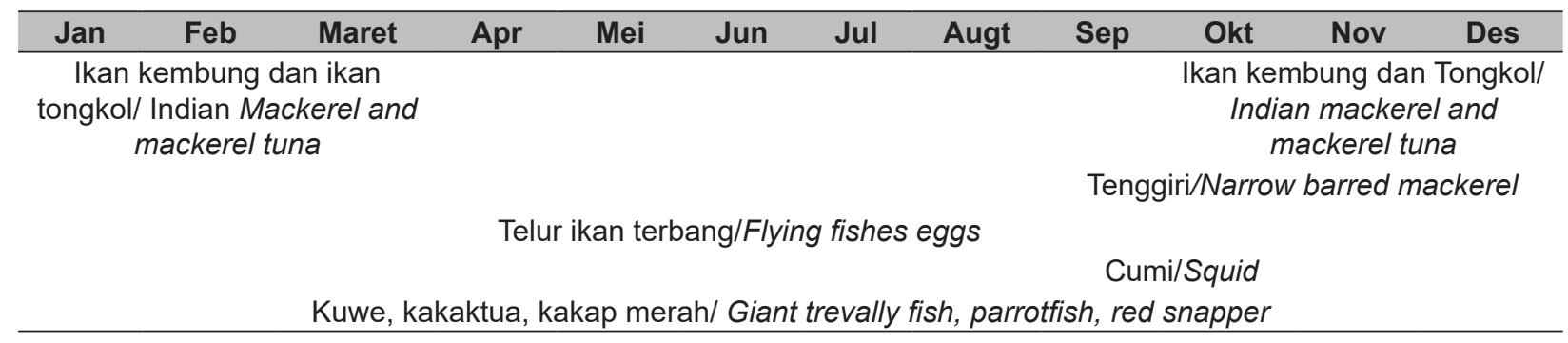


Sementara itu, nelayan lokal di Kota Dobo menggunakan alat tangkap mini purse seine dan pancing tonda. Nelayan mini purse seine menggunakan perahu kayu dengan ukuran panjang 23 meter dan lebar 6 meter. Perahu dilengkapi dengan 2 mesin yang berukuran masing-masing 40 PK. Perahu belum dilengkapi dengan mesin pendingin sehingga nelayan harus menggunakan box pendingin berukuran $50 \mathrm{~kg}$. Satu kapal purse seine terdiri dari 7- 9 orang yang umumnya adalah warga kota Dobo. Nelayan mini purse seine adalah nelayan one day fishing yang akan memulai aktivitas mencari ikan pada pukul $04.00 \mathrm{WIT}$.

Ikan hasil tangkapan umumnya dibawa langsung ke pasar atau ke penampung yang biasa disebut dengan istilah "kontainer". Disebut dengan istilah "kontainer" karena penampung ini akan mengirim ikan ke Jawa (Surabaya dan Jakarta) menggunakan jasa 'kontainer' yang diangkut menggunakan kapal pengangkut. Ikatan antara "kontainer" dengan nelayan melalui pinjaman modal operasional yang diberikan pada setiap trip. Modal operasional yang dibutuhkan Nelayan mini purse seine sebesar Rp1.000.000,00/ trip. Ada 11 orang yang berperan sebagai "kontainer" di seputar kota Dobo.

\section{Nelayan Pendatang Jawa}

Istilah Nelayan pendatang dari Jawa diberikan kepada nelayan yang mencari ikan di perairan Kepulauan Aru dan Arafura yang berciri menggunakan kapal besar berkapasitas $>30$ GT hingga maksimal 149 GT dengan 40-50 orang ABK. Kapal dari Jawa sebagian besar menggunakan alat tangkap purse seine dan pancing cumi yang menggunakan lampu sebagai alat bantu penangkapan ikan. Beberapa informan menceritakan, pada saat musim cumi dan kembung, situasi perairan Kepulauan Aru terlihat menjadi terang-benderang menyerupai kota di tengah laut. Ikan hasil tangkapan nelayan purse seine antara lain ikan kembung (lema) dan tongkol.

Untuk memenuhi kebutuhan pokok nelayan kapal pendatang dari Jawa, perusahaan menunjuk orang lokal yang berperan sebagai perpanjangan tangan perusahaan yang sebagian besar dari Jakarta dan Bagan Siapi-api. Nelayan biasa menyebut dengan istilah 'pengurus' yang bertugas membantu perusahaan dalam memenuhi keutuhan BBM, bahan makanan, Surat Laik Operasional (SLO) dan Surat Persetujuan Berlayar (SPB). Sebagian dari pengurus ada yang berperan ganda mengirimkan ikan hasil tangkapan ke Jakarta dan Surabaya (kolekting) sehingga bertanggung jawab atas pembayaran retribusi ikan hasil tangkapan. Ada 11 (sebelas) pengurus yang berada di Kabupaten Kepulauan Aru dan 3 orang lainnya yang hanya berperan mengirimkan hasil tangkapan( kolekting).

\section{Nelayan Pendatang Sulawesi}

Masyarakat lokal mengakui banyaknya nelayan pendatang dari Sulawesi seperti Bugis, Makasar dan Buton (Sulawesi Tenggara) yang mencari pencaharian hidup di perairan Aru. Nelayan ini merupakan nelayan andon. Sebagian besar nelayan pendatang berasal dari sulawesi menggunakan perahu $>10$ GT. Berdasarkan kebijakan provinsi Maluku, untuk mendapatkan ijin mencari ikan perairan wilayah provinsi Maluku maka pemilik perahu harus tinggal dan menjadi warga provinsi Maluku terlebih dahulu. Hal ini disebabkan Dinas Kelautan dan Perikanan Provinsi Maluku sampai dengan Tahun 2017 belum memiliki kesepakatan (MoU) dengan provinsi lain terkait dengan nelayan andon sesuai dengan Peraturan Menteri KP No.36 tahun 2014 tentang Andon Penangkapan Ikan. Oleh karena itu perahu dari sulawesi ini memiliki status perahu lokal (memiliki SIPI provinsi Ambon) dan bukan perahu andon.

Nelayan pendatang dari Sulawesi, seperti Bugis dan Makassar sebagian besar menggunakan alat tangkap mini purse seine sementara nelayan yang berasal dari Sulawesi Tenggara dikenal oleh masyarakat lokal sebagai nelayan pencari telur ikan terbang. Tabel 2 menjelaskan karakteristik dari masing-masing kelompok nelayan.

Pada Tabel 2 memperlihatkan bahwa nelayan pendatang Jawa menggunakan teknologi yang jauh lebih tinggi, kapal yang memiliki kapasitas lebih besar dan alat tangkap yang bersifat lebih hebat sehingga nelayan lokal jauh tertinggal dari teknologi, jumlah ikan yang tertangkap dan pendapatan. Oleh sebab itu ada potensi kecemburuan sosial ekonomi antara nelayan lokal dengan nelayan pendatang akibat adanya kesenjangan kapasitas dalam pemanfaatan sumber daya. 
Tabel 2. Karakteristik Nelayan di Kabupaten Kepulauan Aru. Table 2. Fishers Characteristic in Kepulauan Aru Regency.

\begin{tabular}{|c|c|c|c|}
\hline $\begin{array}{l}\text { Kategori/ } \\
\text { Category }\end{array}$ & $\begin{array}{c}\text { Nelayan Setempat }{ }^{2} I \\
\text { Local Fishers }^{2}\end{array}$ & $\begin{array}{l}\text { Nelayan Andon3/ } \\
\text { Andon Fishers }^{3}\end{array}$ & $\begin{array}{c}\text { Nelayan Pendatang } \\
\text { (Jawa)/ Migrant Fishers } \\
\text { (Java) }\end{array}$ \\
\hline Kapal/ship & $\begin{array}{l}\left({ }^{*}\right) \text { perahu motor (kayu)/long boat (fiber) } \\
<5 \mathrm{gt} \\
\left({ }^{* *}\right) \text { kapal kayu/wooden ship }<15 \mathrm{gt}\end{array}$ & $\begin{array}{l}\text { - kapal kayu/wooden } \\
\text { ship 5-30 gt }\end{array}$ & $\begin{array}{l}\text { - } \text { kapal kayu/ wooden } \\
\text { ship } \\
\text { - } 30-149 \mathrm{gt}\end{array}$ \\
\hline $\begin{array}{l}\text { Alat Tangkap } \\
\text { dan target ikan/ } \\
\text { fishing gear and } \\
\text { fish target }\end{array}$ & $\begin{array}{l}\text { (*) Suku Aru (tradisional): } \\
\text { - Pancing: kakap/Fishing rod: snaper } \\
\text { fish } \\
\text { - Jaring udang/Trammel net } \\
\text { - Sero/Guiding Barriers } \\
\text { - Jaring insang/Gill nets } \\
\text { ( }{ }^{* *} \text { Non Suku Aru: } \\
\text { - Jaring bobo ukuran } 1,75 \text { Inci: pelagis } \\
\text { Mini Purse Seine mesh size } 1.75 \\
\text { Inch: pelagis } \\
\text { - Tonda: tenggiri/Trolling line: } \\
\quad \text { Narrow barred mackerel }\end{array}$ & $\begin{array}{l}\text { Jaring bobo ukuran } \\
\text { 1,75 Inci: pelagis/Mini } \\
\text { Purse Seine mesh } \\
\text { size } 1.75 \text { Inch: pelagis } \\
\text { Tonda: tenggiri/ } \\
\text { Trolling line: Narrow } \\
\text { barred mackerel }\end{array}$ & $\begin{array}{l}\text { - Jaring bobo ukuran } \\
1 \text { inci /Purse seine } \\
\text { mesh size } 1 \text { inch } \\
\text { - } \quad \text { Pancing cumi: cumi/ } \\
\text { Squid fishing: squid } \\
\text { - } \quad \text { Rawai/long line }\end{array}$ \\
\hline $\begin{array}{l}\text { Alat bantu } \\
\text { penangkapan } \\
\text { Ikan/Aid for } \\
\text { catching fish }\end{array}$ & - & - & - Rumpon/Purse Seine \\
\hline $\begin{array}{l}\text { Asal nelayan/ } \\
\text { origin fishers }\end{array}$ & $\begin{array}{l}\left({ }^{*}\right) \text { Aru } \\
\left({ }^{* *}\right) \text { Bugis-Makassar }\end{array}$ & Bugis-makassar, Buton & $\begin{array}{l}\text { Juwana, Tegal, } \\
\text { Pekalongan, Probolinggo }\end{array}$ \\
\hline $\begin{array}{l}\text { Perijinan/ } \\
\text { Permission }\end{array}$ & $\begin{array}{l}\text { (*)Pencatatan Kapal <5 GT/ Ship } \\
\text { Registration }<5 \text { GT } \\
\left({ }^{* *}\right) \text { SIPI Provinsi Lengkap setelah } \\
\text { memiliki KTP Maluku/SIPI Province } \\
\text { Complete after having Maluku KTP }\end{array}$ & $\begin{array}{l}\text { Tanpa SIPI Andon/ } \\
\text { Without SIPI Andon }\end{array}$ & $\begin{array}{l}\text { Izin pusat/ Central } \\
\text { permission }\end{array}$ \\
\hline $\begin{array}{l}\text { Pemasaran/ } \\
\text { Marketing }\end{array}$ & $\begin{array}{l}\text { - Pasar lokal di Kota Dobo/Local } \\
\text { market in Dobo City } \\
\text { - Penampung atau yang biasa disebut } \\
\text { "kontainer" untuk nantinya di bawa } \\
\text { ke luar Dobo/Container or commonly } \\
\text { called 'container' to be brought } \\
\text { outside Dobo } \\
\text { - Untuk rajungan sebagian dijual ke } \\
\text { nelayan pendatang/For crabs, some } \\
\text { are sold to migrant fishermen }\end{array}$ & $\begin{array}{l}\text { - Pasar lokal di Kota } \\
\text { Dobo/Local market in } \\
\text { Dobo City } \\
\text { - Penampung atau } \\
\text { yang biasa disebut } \\
\text { "kontainer" untuk } \\
\text { nantinya di bawa ke } \\
\text { luar Dobo/ Container } \\
\text { or commonly called } \\
\text { 'container' to be } \\
\text { brought outside Dobo }\end{array}$ & $\begin{array}{l}\text { Dikirim ke Jawa melalui } \\
\text { kapal kolekting dan } \\
\text { pengiriman berinsulasi } \\
\text { ( ex:Temas dan SPIL)/ } \\
\text { Sent to Java via } \\
\text { collectable shipping and } \\
\text { insulated shipping (ex: } \\
\text { Temas and SPIL) }\end{array}$ \\
\hline $\begin{array}{l}\text { Jumlah hari perl } \\
\text { amount every } \\
\text { day trip }\end{array}$ & $\begin{array}{l}\text { - Tangkapan satu hari/ } \\
\text { One day fishing }\end{array}$ & 10-15 hari/10-15 day & 3-8 minggu/3-8 weeks \\
\hline $\begin{array}{l}\text { Jumlah } \\
\text { tangkapan per } \\
\text { trip/amount } \\
\text { cacthing fishing } \\
\text { every trip }\end{array}$ & $5-20 \mathrm{~kg} / 5-20 \mathrm{~kg}$ & 3-4 ton/3-4 tons & $\begin{array}{l}\text { - Jaring bobo } 40-80 \text { ton I } \\
\text { purse seine: } 40-80 \text { tons }\end{array}$ \\
\hline $\begin{array}{l}\text { Jumlah } \mathrm{ABK} / \\
\text { Amount of labour }\end{array}$ & 1-2 orang/1-2 persons & $4-5$ ton/4-5 tons & $\begin{array}{l}40-50 \text { orang } / 40-50 \\
\text { persons }\end{array}$ \\
\hline
\end{tabular}

\footnotetext{
${ }^{2}$ Nelayan setempat adalah nelayan asli Suku Aru $\left({ }^{*}\right)$ dan nelayan non Suku Aru (**) yang sudah menetap di Kepulauan Aru dan memiliki KTP Aru

${ }^{3}$ Nelayan Andon adalah nelayan yang berasal dari luar Provinsi Maluku yang umumnya pada musim-musim tertentu
} 


\section{Pola Relasi Produksi}

Berdasarkan kapasitas kapal yang dipakai, nelayan yang beroperasi di Perairan Aru yang berlabuh di pesisir sekitar Kota Dobo dapat dikelompokkan menjadi empat yaitu nelayan di bawah 5 GT, nelayan $5-<10 \mathrm{GT}$, nelayan 10 - 30 GT dan nelayan di atas 30 GT. Nelayannelayan tersebut saling berinteraksi dan saling mempengaruhi baik secara langsung maupun tidak langsung. Selain antar nelayan, mereka juga berinteraksi dengan pelaku usaha perikanan lainnya seperti pedagang, pengurus, dan pengolah hasil perikanan. Berikut ini interaksi antar pelaku yang terkait dalam pemanfaatan sumber daya ikan di Kota Dobo.

Pada Gambar 3 dapat dilihat bahwa nelayan lokal dan nelayan asli terkadang melakukan kegiatan penangkapan di area yang sama dengan target tangkapan adalah ikan demersa, dan ikan karang. Sedangkan kapal nelayan lokal (>10 GT) memiliki irisan pada wilayah penangkapan dengan kapal pendatang baik dari Jawa ataupun Sulawesi.

Hasil tangkapan ikan oleh nelayan asli dipasarkan melalui pedagang pengumpul di tingkat desa, kemudian di jual ke pasar lokal di kota atau dijual kepada pedagang pengumpul kota/'kontainer'. Demikian halnya dengan hasil tangkapan nelayan lokal juga dipasarkan kepada pengumpul kota/'kontainer' dan ada sebagian kecil yang dijual ke pasar lokal. Pengumpul 'kontainer' ada yang menjual ikan langsung kepada pemesan di luar Dobo menggunakan kapal angkut atau melalui pedagang besar dan dikirim juga melalui kapal laut. Untuk komoditas tertentu dalam jumlah terbatas, produk ikan bisa dikirim melalui jalur via udara.

Untuk memudahan proses kegiatan bongkar muatan ikan dan pengiriman hasil tangkapan, nelayan pendatang bekerja sama dengan pengurus kapal setempat untuk mengkordinasikan selama kapal mendarat (izin bongkar muat, pengisian BBM dan Ransum), termasuk mengirimkan hasil tangkapan. Pengurus kapal melalukan proses packing ikan hasil tangkapan dan selanjutnya mengirimkan hasil tangkapan tersebut melalui jalur laut.

Kedatangan kapal-kapal dari luar ke wilayah kepulauan Aru, secara tidak langsung dapat mendatangkan peluang ekonomi bagi masyarakat, seperti tumbuhnya usaha input produksi seperti penyediaan ransum untuk kegiatan penangkapan, usaha perbengkelan, jasa pengiriman ikan dan tumbuhnya peluang ekonomi dari sektor informal lainnya seperti warung makan, penjual pulsa, dan lainnya. mengandung banyak potensi konflik. Selain menimbulkan peluang ekonomi, kedatangan kapal-kapal tersebut juga dapat menimbulkan

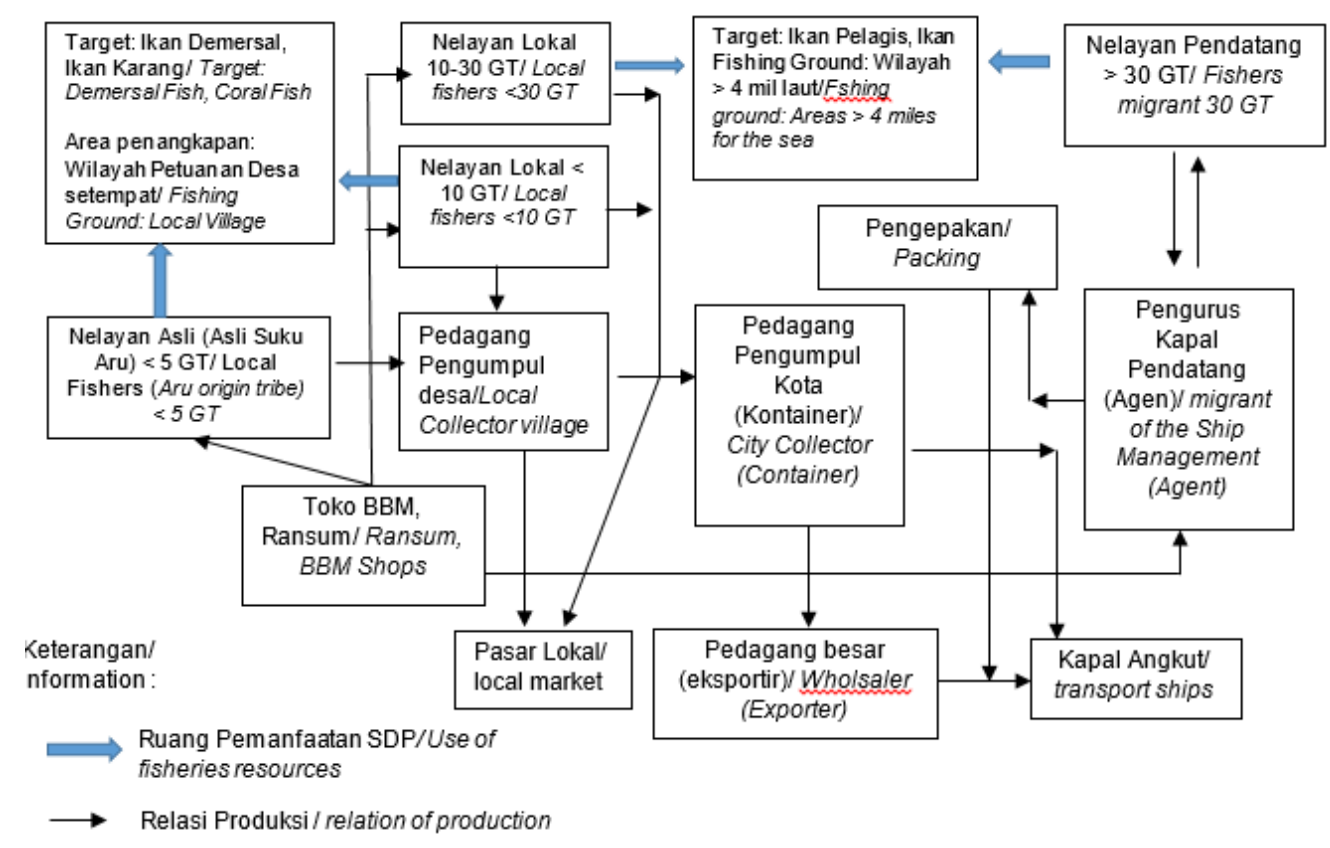

Gambar 3. Pola Relasi Produksi dan Pemanfaatan Sumber Daya di Kab. Kep. Aru.

Figure 3. Patterns of Relation Between Production and Utilization of Resources in Kepulauan Aru Regency. 
konflik. Hal ini dikarena aktivitas perikanan tangkap yang dilakukan tidaklah semata-mata merupakan aktivitas ekonomi yang bebas dari pengaruh sosial. Interaksi antara nelayan pendatang dengan nelayan lokal dan pelaku usaha perikanan dapat memunculkan potensi konflik yang diantaranya timbul karena adanya kecemburuan terhadap hasil tangkapan yang didapat (penurunan hasil tangkapan nelayan lokal).

\section{Potensi Konflik Antar Nelayan}

Kebijakan pengalihan wilayah tangkapan (fishing ground) kapal berukuran > 30 GT dari WPP 712 ke WPP 718 yang dilakukan oleh pemerintah pusat (Kementerian Kelautan dan Perikanan) tidak hanya memberikan dampak positif, namun di lain pihak ternyata memiliki potensi konflik baik diantara sesama nelayan pendatang maupun dengan nelayan lokal kepulauan Aru.

Nelayan lokal yang menggunakan mini purse seine berpotensi konflik dengan nelayan pendatang Jawa yang memakai purseseine sebab meskipun wilayah tangkapan berbeda namun memiliki target ikan yang sama. Ketidakseimbangan kepemilikan alat dan teknologi penangkapan yang digunakan menjadi salah satu sumber masalah. Nelayan pendatang dari Jawa yang menggunakan kapal berukuran > 30 GT umumnya menggunakan alat tangkap yang lebih canggih dan memiliki kapasitas yang besar. Teknologi GPS dan VMS pun turut serta dalam kegiatan penangkapan ikan yang diilakukan, sehingga kapal-kapal tersebut mampu menangkap dengan lokasi tangkapan yang menyesuaikan dengan keberadaan ikan. Selain itu, nelayan pendatang mempunyai rumpon yang juga dianggap sebagai salah satu penyebab nelayan lokal mengalami penurunan hasil tangkapan.

Nelayan lokal yang menggunakan alat tangkap pancing tonda berpotensi konflik dengan nelayan pendatang Jawa yang menggunakan purse seine. Hal ini disebabkan ikan yang menjadi target utama tangkapan nelayan tonda adalah tenggiri, sementara nelayan purse seine menangkap ikan yang menjadi makanan tenggiri. Berkurangnya sumber makanan tenggiri dianggap sebagai penyebab menurunnya hasil tangkapan nelayan. Bagi nelayan lokal yang menggunakan alat tangkap tonda, nelayan purse seine dianggap lebih merugikan dari pada nelayan cumi yang terkadang juga menangkap tenggiri di luar musim cumi. Hal ini disebabkan yang ditangkap nelayan cumi hanya tenggiri dan bukan sumber makanan tenggiri.

Nelayan lokal dengan nelayan pendatang dari Jawa karena perbedaan penggunaan ukuran mata jaring purse seine. Ukuran mata jaring purse seine yang digunakan oleh nelayan pendatang dari Jawa adalah 1 inch, sementara nelayan lokal menggunakan ukuran mata jaring 1,5 - 1,75 inch. Perbedaan ukuran mata jaring menjadi potensi konflik tersendiri. Meskipun demikian, ukuran mata jaring nelayan pendatang Jawa sudah sesuai dengan Permen KP No.71 Tahun 2016 tentang Jalur Penangkapan Ikan dan Penempatan Alat Penangkapan Ikan di Wilayah Pengelolaan Perikanan Negara Republik Indonesia. Ukuran mata jaring yang lebih kecil yang digunakan oleh nelayan pendatang Jawa dianggap sebagai penyebab penurunan hasil tangkapan nelayan lokal. Nelayan lokal meyakini ukuran mata jaring yang digunakan merupakan salah satu bentuk kearifan lokal untuk melindungi keberlanjutan sumberdaya.

Potensi konflik yang timbul akibat terganggunya sistem permodalan dan pemasaran yang selama ini sudah berjalan. Kapal mini purse yang dioperasikan oleh nelayan lokal mendapatkan modal dari operasional dari para penampung atau bakul yang disebut dengan istilah lokal "kontainer". Disebut dengan 'kontainer' karena penampung akan mengirim ikan ke Jawa (Surabaya dan Jakarta) menggunakan jasa 'kontainer' yang diangkut menggunakan kapal pengangkut. "kontainer" akan membuat ikatan dengan memberikan pinjaman modal operasional sebesar Rp.1.000.000,- per trip kepada nelayan purse seine, dengan harapan 'kontainer' mendapatkan pasokan rutin ikan segar dari hasil yang didapatkan nelayan. Di Kota Dobo, setidaknya terdapat 11 orang yang menjalankan usaha dan berfungsi sebagai "kontainer".

\section{PENUTUP}

Kebijakan relokasi wilayah tangkap kapal berijin pusat ( > $30 \mathrm{GT}$ ) dari WPP 712 ke WPP 718 memberikan dampak peningkatan jumlah kapal secara signifikan yaitu sebesar 293,2 $\%$ atau sebanyak 1016 kapal yang tersebar di beberapa landing base diantaranya Dobo, Merauke, dan Kaimana sejak periode 2015Maret 2018. Peningkatan frekuensi kedatangan kapal berijin pusat terjadi pada bulan September hingga Desember yang merupakan musim banyaknya ikan pelagis kecil sebab kapal berijin pusat ini menggunakan alat tangkap purse seine. Kedatangan kapal berijin pusat ke wilayah perairan 
Aru memberikan dampak bagi nelayan lokal. Dampak positif adalah meningkatnya aktivitas perekonomian yang dapat mendatangkan peluang ekonomi bagi masyarakat. Tumbuhnya usaha input produksi seperti penyediaan ransum untuk kegiatan penangkapan, usaha perbengkelan, jasa pengiriman ikan dan tumbuhnya peluang ekonomi dari sektor informal lainnya seperti warung makan, penjual pulsa, dan lainnya. Namun di sisi lain kedatangan nelayan kapal berijin pusatmengandung banyak potensi konflik. Kesenjangan kapasitas dan teknologi penangkapan antara nelayan pendatang dan lokal dapat menimbulkan kecemburuan akibat penurunan hasil tangkapan dari sisi nelayan lokal.

Terdapat dua opsi rekomendasi beserta implikasi rekomendasi yang dapat digunakan dalam pengambilan kebijakan. Opsi rekomendasi kebijakan pertama adalah, melakukan pengkajian kembali jumlah izin kapal penangkapan ikan dan rumpon di WPP 718 sesuai dengan potensi stok ikan yang teridentifikasi. Implikasi rekomendasi dari rekomendasi ini adalah berupa: (1) Ditjen Perikanan Tangkap melakukan pengkajian kembali tentang jumlah izin kapal (SIPI) pusat yang beroperasi di WPP 718. Kuota / pembatasan izin kapal oleh pusat dilakukan juga berdasarkan rekomendasi pemerintah daerah; (2) Ditjen Perikanan Tangkap melakukan pengkajian kembali tentang jumlah izin penggunaan rumpon sebagai alat bantu penangkapan di WPP 718; (3) Pemerintah pusat mengkaji ulang ukuran minimum mesh size untuk meningkatkan selektivitas hasil tangkapan guna keberlanjutan usaha perikanan; dan (4) Pemerintah daerah cq Dinas KP Propinsi Maluku berkoordinasi dengan Dinas Perikanan Kabupaten setempat lebih mengaktifkan kembali Pokmaswas untuk bersamasama dengan pihak berwenang (DJPSDKP KKP, Polairud, TNI AL) melakukan pengawasan atas praktek perikanan di WPP 718.

Sementara opsi rekomendasi kebijakan kedua adalah, melakukan penguatan Kelembagaan Lokal dan Peran Masyarakat Lokal di WPP 718. Implikasi rekomendasi dari rekomendasi ini adalah berupa: (1) Pemerintah Propinsi Maluku segera menginventarisasi dan menetapkan desa-desa adat berikut wilayah adatnya untuk dimasukkan ke dalam RZWP3K agar memberikan kepastian hukum bagi pelaksanaan pengelolaan perikanan berlandaskan wilayah dan aturan adat; (2) Pemerintah Daerah menyusun program dan kegiatan pembinaan terhadapABKIokal (keterampilan dan pengetahuan); (3) Pemerintah pusat menyusun aturan turunan yang berisi kewajiban merekrut tenaga setempat (nelayan lokal) sebagai ABK pada kapal > 30 GT; dan (4) Pemerintah Daerah menyusun program dan kegiatan untuk melakukan scale up armada penangkapan nelayan lokal secara bertahap agar mampu bersaing dengan nelayan pendatang.

\section{UCAPAN TERIMA KASIH}

Tulisan ini merupakan bagian dari penelitian "IMPLIKASI NELAYAN PENDATANG TERHADAP POLA USAHA NELAYAN LOKAL DI KEPULAUAN ARU" dengan sumber dana berasal dari DIPA BBPSEKP T.A. 2018. Untukitu penulis mengucapkan terima kasih kepada Yayan Hikmayani,M.Si sebagai Penanggung Jawab Output kegiatan penelitian ini. Penulis juga menyampaikan terimakasih yang sebesar-besarnya kepada para narasumber dan pembantu lapang yang telah membantu penulis dalam mengumpulkan data. Selain itu, ucapan terima kasih juga kepada segenap tim redaksi yang telah memberikan masukan dan arahan untuk penyempurnaan tulisan ini.

\section{DAFTAR PUSTAKA}

Arikuntho, S. (2006). Metodologi Penelitian. Jakarta : Rineka Cipta.

Balai Besar Riset Sosial Ekonomi Kelatan dan Perikanan (BBRSEKP). 2018. Ratusan Kapal Eks Cantrang dari Jawa Melaut di Perairan Dobo Aru. Kenapa. (http://kmsv2.sosialekonomi.com/2018/03/13/ ratusan-kapal-eks-cantrang-dari-jawa-melaut-diperairan-dobo-aru-kenapa/ ). (Diakses tanggal: 13 Mei 2018).

Cantika, F.S., Arifin, M., Prayoga, A.P. \& Sanjaya, A. (2017). Potret Aktivitas Ekonomi Masyarakat Adat Kabupaten Kepulauan Aru. Forest Watch Indonesia dan LPPM IPB. Bogor.

Dewan Perwakilan Rakyat Komisi IV. (2014). Adanya Kecemburuan Nelayan Tradisional Kepulauan Aru. Diambil dari Laman DPR RI http://www. dpr.go.id/berita/detail/id/19421/t/Adanya+Kecemburuan+Nelayan+Tradisional+Kepulauan+Aru. Retraived: pada tanggal 1 Mei 2019.

Dunn, W.N. (2000). Pengantar Analisa Kebijakan Publik. Yogyakarta: Gadjah Mada Press.

Gunawan N.A, Ruyadi, Y., \& Alia M.N. (2017). Analisis Perubahan Kondisi Sosial-Ekonomi Masyarakat BlokPekauman DesaAstana Dengan Keberadaan Tradisi Ziarah Makam Sunan Gunung Jati Di Cirebon. Sosietas, Vol. 7, No. 1, 2017.

Keputusan Menteri Kelautan dan Perikanan No. 50 tahun 2017 tentang Estimasi Potensi, Jumlah tangkapan yang Diperbolehkan, dan Tingkat Pemafaatan Sumber Daya Ikan di Wilayah Pengelolaan Perikanan Negara Republik Indonesia. 
Miles, B. M. \& Huberman, M. (1992). Analisis Data Kualitatif Buku Sumber Tentang Metode-metode Baru. Jakarta: Universitas Indonesia Press.

Moleong, L.J. (2005). Metodologi Penelitian. Bandung: Remaja Rosda Karya.

Nasir, M. (2005). Metode Penelitian. PT. Ghalia. Indonesia.

Peraturan Menteri KP no. 1 Tahun 2009 Jo No.18 Tahun 2014 tentang Wilayah Pengelolaan Perikanan Republik Indonesia (WPP).

Peraturan Menteri Kelautan dan Perikanan No.36 Tahun 2014 Tentang Andon Penangkapan Ikan

Peraturan Menteri Kelautan dan Perikanan No 71 Tahun 2016 tentang Jalur Penangkapan Ikan dan Penempatan Alat Penangkapan Ikan di Wilayah Pengelolaan Perikanan Negara Republik Indonesia.

Ririhena, J.E. (2017). Kondisi Perikanan Tangkap di Kabupaten Kepulauan Aru. 2017. Jurnal Hibualamo: Seri IImu-IImu Alam dan Kesehatan Vol. 1 No.1 Tahun 2017. LPPM Universitas Hein Namotemo. Halmahera Utara.

Suman, A., Irianto, H.E., Satria, F. \& Amri, K. (2016). Potensi dan Tingkat Pemafaatan Sumber Daya Ikan di Wilayah Pengelolaan Perikanan Negara Republik Indonesia (WPP NRI) Tahun 2015 serta Opsi Pengelolaannya. Jurnal Kebijakan Perikanan Indonesia. Volume 8 No.2 Nopember 2016. Pp.97- 110.

Surat Edaran Direktur Jenderal Perikanan Tangkap Nomor B.664/DJPT/PI.220/VI/2017 Tanggal 19 Juni 2017 Tentang Perpanjangan Masa Peralihan Alat Penangkapan Ikan Pukat Tarik Dan Pukat Hela Di WPPNRI.

Weimer, D.L \& Vining, A.R. (1998). Policy Analysis: Concepts and Practice. Prantice Hall. 